\title{
Can Doctors Maintain Good Character? An Examination of Physician Lives
}

\author{
Saba Fatima ${ }^{1}$ \\ Published online: 5 March 2016 \\ (C) Springer Science+Business Media New York 2016
}

\begin{abstract}
Can doctors maintain good character? This paper shifts the focus from patient care to ethical considerations that bear on the physician and impact her as a person. By decentering patient care, the paper highlights certain factors that habituate a particular way of reasoning that is not conducive to inculcating good character. Such factors include, standards of professionalism, being influenced by external monitors, and emphasis on adherence to guidelines. While such factors may benefit patients, they often adversely affect the character of physicians.
\end{abstract}

Keywords Character Physician P Professionalism · Virtue $\cdot$ Empathy $\cdot$ Compassion

Dr. Philips' day at the clinic was finally ending. She had seen twenty-five patients in a span of eight hours, and just as she was ready to go home, her pager buzzed. Her forty-week-pregnant patient was just admitted in active labor, only four $\mathrm{cm}$ dilated. As she changed into her green scrubs, she could not help but think about missing yet another family dinner and possibly staying on-call overnight. Natural labor can take up to sixteen hours to deliver a baby. However, if the labor is augmented with medication or with early breaking of the amniotic fluid, it can progress faster. Her patient was full term and could potentially benefit from a timely delivery, but an induced labor could also increase the patient's chances of a Caesarian birth. Dr. Phillips decides to proceed with induced labor. The next morning, Dr. Phillips is admiring the picture of herself with the baby and the mother. Of course she missed seeing her kids for dinner, but she was able to rest before her morning shift, and the new mother and baby were doing well.

This paper examines the myriad reasons that a doctor invariably takes into consideration while making medical decisions within everyday settings and the way that such reasoning impacts character. By 'everyday setting,' I refer to the real life circumstances that physicians in the United States operate in, where established standards of care aim at achieving optimum

Saba Fatima

sfatima@siue.edu

1 Philosophy Department, Southern Illinois University Edwardsville, Box 1433, Edwardsville, IL 62026, USA 
results, all the while drastically falling short of the ideal. Furthermore, the paper focuses on examining the physician's character such that what is generally regarded as the telos of the profession $^{1}$ - the activity of healing the patient - is not a central concern in guiding this ethical query. That is to say, this project is not primarily aimed at understanding good character in the context of patient care; rather it is aimed at the ways that everyday medical settings affect the physician's character, both within the professional and the personal realm. I claim that the two spheres - professional and personal - are inseparable. Character traits developed in one realm are bound to bleed into other spheres of life. The paper situates patient concerns as a secondary concern and examines the physician's character for the physician's sake. ${ }^{2}$

Before I begin to speak of the character of a physician, it would help to shed some light on why a focus on character is helpful. The question of the applicability of virtue theory has been widely discussed, both within the field of medical ethics (Hursthouse 1999) and within value theory (Gardiner 2003; Jansen 2000; Pellegrino \& Thomasma 1993; Putman 1988). Here, my aim is to highlight how considerations of character can illuminate certain deficiencies within physicians' lives, which otherwise would not be as prominently visible. This focus on character is not solely within the realm of normative ethics, but one that is also interested in how doctors actually behave within everyday circumstances that they encounter. A focus on character, as it responds to and within certain social structures, illuminates how we in fact operate when faced with ethical concerns. This concentration on the physician's character within everyday clinical norms does not diminish the role of medical expertise, rules and regulations, and professional norms as essential pre-requisites to practicing medicine. My particular focus merely aims to add a dimension to the practice of medicine, which can be roughly categorized as a consideration of the physician's character for her own sake.

I begin with a brief discussion of physician's character within a virtue ethics framework and then examine the sort of circumstances that may impede the inculcation of specific virtues, namely empathy and compassion. I argue that often the very aspects of medical practice which are designed to ensure consistency in the quality of care that each patient receives - professionalism, time management, set standards of care, and competitive training environment - are precisely the aspects of medical practice that are detrimental to the formation of good character within the physician. In the final section of the paper, I discuss the existence and malleability of character. The issue of physicians' character encompasses numerous concerns, not all of which can be sufficiently covered within one article. My purpose here then is to consider some of the current norms that may adversely affect physicians as human beings.

\section{The formation of doctors}

In order to understand what it means for a physician to have good character, I begin with explicating the notion of virtue within an Aristotelian framework. In Nicomachean Ethics, Aristotle defines virtue as "a state of character concerned with choice, lying in a mean" not determined by principle but cultivated through exercise by a person of practical wisdom (1989, II. 6:1106b9-1107a1). Moreover, virtue for Aristotle is a disposition toward making the right choice. Within contemporary literature, Rosalind Hursthouse (1999, 10-11) emphasizes that virtue is not an attitude but that the virtuous person must reason in characteristic ways by taking relevant things into consideration. That is to say a trait is only a virtue if it is exercised "at the right times on the right grounds towards the right people for the right motive and in the right way" (Aristotle 1989, II. 6:1106b9- 
1107a1, emphasis mine). It is this notion of virtue that I take into consideration in my discussion of the doctor's character.

The task at hand for the doctor is to engage in the activity of healing the patient, often interacting with patients in their most vulnerable state. The ideal qualities sometimes associated with a physician are beneficence, trust, empathy, and compassion (Pellegrino 2008, 271 273). However, without these qualities, a person cannot lead a eudaimonic life or possess the sort of happiness worth having. For what constitutes a eudaimonistic life, it is sufficient to say, for the purpose of this project, that a person who is selfish, apathetic, and/or bears maleficence towards others is not a person of good character and bears little chance of possessing a deep sense of happiness. ${ }^{3}$ And so, while these traits are a benefit to patient care, they are also valuable in terms of a person having good character for the person's own sake. It is this focus on the character - as opposed to patient care - that I want to retain in examining the physician.

As in any profession, the environment in which one practices continually molds character. That is to say, for physicians ethical considerations and clinical practice are inseparable. Just as residency programs are designed to make medical procedures routine for the future attending, the training provided also habituates the verbal and nonverbal scripts ${ }^{4}$ for interacting with the patient. Similarly, while some residency programs may focus on what to do to avoid a lawsuit, for example during conferences or discussion sessions focused on legal requirements, many others teach those very same requirements as essential to ensuring a patients' basic rights and deliverance of proper care. After all, patient-centered groups have fought hard for rules that ensure that physicians do not abuse their privilege at the expense of their patients (e.g. Reverby 2012). These norms surrounding patient care are situated within verbal and non-verbal cues of the resident's attending, their surrounding infrastructure, work politics, etc. Kathryn Montgomery, a leading bioethicist in medical humanities, describes the absorption of clinical norms as akin to osmosis, "[T] he solution undergoes slow change molecule by molecule, and there's no going back" $(2005,162)$. This analysis of the transformation of the person is in line with Aristotle's view that formative years are crucial to character stabilizing within oneself. He states that "it makes no small difference, then, whether we form habits of one kind or another from our very youth; it makes a very great difference, or rather all the difference" (Aristotle 1989, II $1 \& 1103$ b). It is within these clinical norms that the physician in-training habituates how she reasons and practices medicine, all the while slowly molding her character within the inevitably less-than-ideal conditions she trains in. It follows that through medical school and residency, physicians are primed to transform, or more appropriately, habituate traits necessary to function within the profession.

I explore the virtues of empathy and compassion as examples of traits that are considered part of the professional realm. More importantly, for the purpose of this paper, empathy and compassion are also linked deeply with the formation of good character, independent of one's goal of providing quality patient care. In considering these two virtues, I shed light on the sort of norms that serve as impediments to the formation of good character.

\section{"I understand this may be difficult..." - empathy}

A physician's ability to empathize is often presented as vital within primary care ethics (Lelorain et al. 2012, Stepien and Baernstein 2006). A 2012 study by Canale et al. revealed that empathy in primary care physicians was significantly associated with better clinical outcomes for patients with type 2 diabetes. Empathy was quantified with a well-validated 
questionnaire that measured the doctor's understanding of the patient's experiences, concerns and perspectives, as well as her ability to communicate this understanding to the patient. According to this study, patients were more likely to follow their physician's prescriptions if she was empathetic.

While empathic posture affects a patient's compliance, I argue that doctors often face impediments to habituating virtues like empathy and that failing to recognize opportunities to exercise empathy within the professional realm most certainly impacts one's character as a human being, beyond one's striving to be a good doctor.

For some, empathy can be loosely understood as a viscerally felt comprehension of another's emotional state (Piper 1991). However, a particular understanding within medical ethics literature, "defined empathy in the context of medical education and patient care as a predominantly cognitive (as opposed to affective or emotional) attribute that involves an understanding (as opposed to feeling) of patients' experiences, concerns, and perspectives combined with a capacity to communicate this understanding" (Hojat 2009). Such an explication of empathy is helpful in the sense that it allows for recognition of the fact that being emotionally tied to one's patient can also cripple a physician's ability to do her job. Hojat's understanding of empathy allows for the doctor to comprehend the patient's experience without the undue strain of affectively experiencing patients' agony in their most vulnerable state. Furthermore, Nancy Snow argues that at least some familiarity is needed with the person toward whom one is empathic: "If we were not sufficiently similar to those with whom we empathize, imaginatively projecting ourselves into their circumstances would not be a reliable guide to how they feel, nor would attempts to simulate their thoughts and feelings be empathically accurate" $(2000,71)$. For Snow, it is essential for empathic identification that there is actual similarity and a belief about one's similarity to another.

One possible reason for not understanding the patient's perspective is that the physician and her patient frequently occupy complicated social hierarchies. One such apparent hierarchy is the significant disparity between physician compensation packages ${ }^{5}$ and the average American household salary. ${ }^{6}$ Consequently, doctors are often unfamiliar with the daily lived experiences of patients who are of lower socio-economic status than themselves. Some physicians then struggle to manage their own expectations of their patients and fail to address or understand the opportunities available to them. These factors affect the physician's judgment of the patient's culpability in the patient's own suffering. A physician may blame the patient for noncompliance because the doctor does not/cannot narrate the lived experience of poverty and how it affects compliance of treatment. And although many physicians have occupied social locations within similar narratives of poverty at some points in their lives, many perceive themselves as a testament to the fact that hard work pays off, further discounting their privilege and luck (Kraus MW \& Keltner D 2013). ${ }^{7}$ As such, these doctors are more likely to blame their patients for their predicaments. In cases of income disparity, it is nearly impossible to cultivate empathy as a virtue because the physician is not an accurate guide to her patients' lives and consequently cannot imaginatively project herself into another's lived experiences on a consistent basis in her practice. In such a scenario, how she may live her personal life of relative affluence affects her disposition with patients. Similarly other social structures and locations may also play a role in impeding the ability to empathize with another, such as race, sexuality, and religion.

A 2008 study by Morse, Edwardsen, and Gordon found that physicians overwhelmingly miss opportunities to express empathy to their patients. The study identified 'empathic opportunities' in discussions with lung cancer patients as moments where the physicians could 
have responded to patient concerns such as fear of illness and death, mistrust about care, the health care system, and confusion about their treatment plan. They found that the physicians missed ninety percent of opportunities to respond empathically and restricted themselves to bio-medical responses to patient concerns. ${ }^{8}$ This is an alarming result not only from the perspective of the cancer patient but also, for the purpose of this project, because of what such results mean for the character of the doctor as a human being. Similarly, another analysis of data from three longitudinal and six cross-sectional studies found that empathy declines during one's medical training as physicians lean more toward 'professionalism.' Among key factors cited in this decline were 'increased contact with patients' and 'physician distress,' and they resulted in depression and reduced quality of life for the physician (Neumann et.al. 2011). The study highlights the replacement of empathic affective response with what is deemed as more 'professional' behavior, such as citing relevant statistics to patients, while ignoring said fears or patients' feelings of mistrust.

This lack of exercising one's ability to recognize opportunities to express empathy in certain aspects of one's life may also affect one's disposition or way of reasoning in other aspects of life that require one to recognize similar opportunities. Let me argue this by addressing an objection to this claim. A possible criticism may be that one ought to compartmentalize professional obligations from private ones. We do not expect our friends who are professors in Compositional Writing to be constantly critiquing our language, nor do we expect our physician friends to give us diagnoses at parties (though some family members do expect at least a drive-by differential diagnosis for the occasional unexplained rash). If a physician is not empathic to her patients and can adequately treat the illness at hand, then some may argue that such demeanor is appropriate within the professional domain. In the final section of the paper, I discuss this concern from the lens of situationism; however, here I only address the issue of compartmentalization of dispositions.

Compartmentalization is possible only when there is sufficient degree of mutual exclusivity between the sorts of obligations associated with any particular role. A situation that requires medical expertise is likely to occur within clinical settings rather than at home. Technical knowledge in the field of medicine is not deployed generally in other settings. ${ }^{9}$ However, in the case of virtues such as empathy and compassion, there are significant overlaps in the rolerelated obligations between medical settings and one's personal life. Such virtues require one to practice recognizing the opportunity to exercise the trait. A deficiency of the trait in one realm becomes habituated and inevitably bleeds into other instances where one fails to recognize similar obligations. This is because the person has not sufficiently exercised the faculty necessary to recognize and respond when one encounters another's vulnerability.

\section{"We care about your well-being" - compassion}

Let me examine another trait, the virtue of compassion, which perhaps gets more opportunities to be practiced by doctors, and is even more illuminating of the significance of the particular focus on the physician's character for the physician's own sake. Compassion encompasses not merely sympathetic feeling toward the plight of others (the patient in this case) but also a strong desire to alleviate it for its own sake. Some bioethicists have argued that a patient's healing cannot be complete without the physician's compassion such that the doctor may adjust the treatment "to the particularities of this patient's life story, time of life, and so forth" (Pellegrino 2008, 272). 
I claim that while certain sorts of rules and regulations may be necessary for proper patient care, ${ }^{10}$ such monitoring has an unintended consequence of exerting an external motivator for the scripts of compassion and can consequently impact the doctor's character adversely. If a physician is regulated to perform the scripts of compassion, it can become a ritual without proper motivation: routine, perfunctory, and a mere necessary function of the rules and regulations that are in place. For example, in the United States, hospitals and other inpatient facilities monitor patient satisfaction with Hospital Consumer Assessment of Healthcare Providers and Systems (HCAHPS) scores. Similarly, most large group outpatient practices also have internal patient satisfaction surveys to track the quality of their doctors. As larger corporations are acquiring small offices and reimbursements are becoming more quality driven than volume driven, physicians have to tailor more to their patients to stay competitive. Generally speaking, if a physician is rated low, it adversely affects their compensation. ${ }^{11}$ Thus, while many physicians may exercise an appearance of compassion, their motivation may be linked to fiscal incentives instituted through external monitors such as the HCAHPS.

A relevant point of consideration is that most professions today have evaluations and accountability that monitor a person's performance, and yet, as in the case of university professors, we do not assume that external monitors (such as student evaluations) drastically shift the instructor's motivation and reasoning in how she teaches. Physicians, however, have additional components of dealing with very vulnerable population and an over-looming fear of litigation (Studdert et al. 2005; Mello et al. 2013). Several studies have shown that physicians often practice what is termed as defensive medicine, i.e. order tests or procedures, primarily due to fear of litigation (Kessler \& McClellan 1996, Studderrt, et al. 2005; Katz et al. 2005).

Hence, the doctor may follow protocol, order all of the right tests, treat the patient with compassion, and learn how to respond to patients in accordance with rules set to ensure quality patient care. But this practice of responding the right way is not habituated within the doctor's character for the right reasons. ${ }^{12}$ Compassion gets reduced to a caricature of itself, a part of the script, a script that may even 'work' on the patient's end but nonetheless partially motivated by external monitors. Patients may perceive it as genuine compassion and consequently, value, trust, and follow through with their doctor's judgment more so. However, I argue that this caricature of compassion is detrimental to one's character.

For Aristotle, the virtuous person is one whose passions and deliberation are aligned. The person takes pleasure in doing what she thinks is best (Aristotle 1989, I 8 \& III 9). In the doctor's situation, her deliberations and the appearance of the action are not aligned, nor is the performance of the action particularly geared toward the trait's habituation. One's deliberations are not only partially derived from the scripts habituated through residency programs but also affected by an awareness of end-of-month statistics about number of patients seen, codes patients were billed at, and a constant drive to maintain high HCAHP scores. Hospitals and practice centers worry that patients may file formal complaints, or worse, sue the physician, not for malpractice but because the negligence is accompanied by a physician that blatantly did not display care. Even a doctor's ethics training isn't given from the perspective of her own character but through proven guidelines and scripts toward the professional end of healing the patient. These guidelines frame the physician's behavior within the confines of what the physician owes to the patient, of what is expected of her by her employer, and/ or sometimes even what she ought to do to avoid potential legal action against her. Such a setting actively impedes the formation of a good character. In fact, the case of compassion illustrates how $a$ framework that fails to take into account the doctor's character for the doctor's sake, often reduces virtues associated with the medical profession to caricatures of themselves. That is to 
say, the transformation of medicine towards patient outcomes simultaneously invokes the virtues of medical practice while reducing them to caricatures of themselves. And while the quality of patient care may not deteriorate, the character of the person who follows these set procedures and scripts suffers.

\section{Lost in quality patient care - character}

It may seem odd to say that physicians live a life that is lacking. After all, they have the material existence necessary to embody certain virtues, such as the means to pursue the arts and to develop traits such as generosity. Aristotle himself recognizes that adequate material goods are necessary (but not sufficient) for flourishing (Aristotle 1989, 1099a31-1099b8, 1101a14-16, 1153b14-21). Yet, such a claim is not met with surprise. Shanafelt, Sloan, and Habermann highlight the neglect of physician's own personal well-being and stress the significance of further research "to help students develop a personal strategy to promote wellness and create work-life balance" $(2003,517)$. An emphasis on the character of a physician allows for the development of one such thread of strategies focused on the self for the self's own sake. In this section, I focus on character more generally, the ways that it is impacted by time constraints and physician burnout, and argue that standards of care and regulation hinder the inculcation of good character.

A number of factors may influence a physician's daily scripts and norms, including awareness of hospital/office resources, high cost of reimbursements from insurance providers, the temperament of management or resident's attending, maintenance of collegial relationships with staff, and the competitive nature of medical training. Such considerations supplement the Hippocratic Oath of doing no harm, and with time, these considerations become inseparable aspects of one's reasoning.

A realistic limitation that physicians face in affectively responding to each patient is the issue of time management (Braddock and Snyder 2005, Linzer et al. 2000). Indeed, it is impossible to weigh every decision in its appropriate social context and reflect on its effect on the patient's state of mind, especially when the physician has to round on fifteen more patients, dictate notes, answer pager calls, follow up on test reports, bill patient codes, and respond to patient messages. However, it is precisely this concern about time management that highlights the importance of habits, dispositions, and character. Daily hectic schedules do not always allow time to deliberate on moral choice; this is where habitual scripts step in and play a crucial role in one's decision-making process. As mentioned before, these habitual verbal and nonverbal attitudes are formed in clinical rotations and residency programs, and the scripts/norms become automatically operative in stressful, time-sensitive situations that doctors face daily. In fact, stressful situations themselves eventually become scripted and normalized in regards to how one reasons at any one point. In such situations, it is imperative that a physician is trained to reason correctly through medical school and residency, so that the right attitude and ethical posture come effortlessly. Tunnel vision focused solely on the activity of healing the patient obscures the cumulative effects of these indispensable logistical considerations shaped over years within a physician. The effects only become visible with focus on the character of the physician for the physician's own sake.

Another such cumulative effect that has received considerable attention in medical humanities is what is termed as 'physician burnout,' characterized as physical and emotional exhaustion from which it is hard to recover during one's time off (Schaufeli and Greenglass 
2001), a callous attitude toward the patient, reduced sense of personal accomplishment (Maslach et al.1996, 20), and "an erosion of the soul caused by a deterioration of one's values, dignity, spirit and will" (Maslach and Leiter 1997). Burnout has been attributed to the conditions in which physicians function and has been linked to self-perceived medical errors (West 2009). However, my paper shifts the focus from harm to the patient to an emphasis on the damage to the physician's character. American physicians, especially those at the front line of care access (family medicine, general internal medicine, and emergency medicine), experience burnout at higher rates than other American workers (Shanafelt et al. 2012). According to one study, self-reported burnout amongst intern residents rose sharply from the beginning to the end of their first postgraduate year (Rosen 2006). Another study reported that the level of burnout was inversely correlated to the medical student's empathy scores (Thomas 2007). That is to say, the longer the physician practices, the more likely she is to experience burnout and that burnout contributes to eroding virtues such as compassion, empathy, and pride in one's work.

Concern about physician burnout is significant for my project because burnout transforms the person. It erodes at deeply embedded states of character of good people by continually providing them circumstances that habituate a detrimental posture. Many medical students are idealistic about what their future job involves and rightly so. Their idealism is not misplaced because being a physician entails opportunities to lead a meaningful life, a life where one is engaged in a continual project of positive value, helping others through their sufferings, and developing one's intellectual and moral virtues with (more than) sufficient material goods. However, factors such as an overburdened schedule, disciplinary external monitors, and / or competitive training environment dislocate the focus from these ideals to efficiency of the system. There is a palpable loss of integrity in one's work, replaced by worries of standards of care and reimbursement concerns. Gradually, the anxiety also becomes normalized, and these concerns become the framework in which physicians reason.

There is much hope as some hospitals have instituted techniques such as mindfulness and narrative medicine where the primary focus is on physical well-being. Mindfulness involves practicing awareness of how physicians are feeling and how that may influence their decision making capacity, while various forms of narrative medicine involve the practice of recognizing, absorbing and working through the narratives of illness from the physician and patient's perspectives. Both mindfulness and narrative medicine aid in regaining and retaining empathy and compassion as part of oneself, traits that the practice of medicine often erodes in the world of hospitals. Such strategies ought not to be aimed at creating practical uniform standards of patient care, otherwise they too can become yet another scripted norm, lacking proper motivation. Rather, their aim often is and ought to be general well-being of medical professionals and as a consequence, an exercise of moral faculties.

In this paper, I have not been concerned with doctors who commit negligence or who purposely circumvent regulations at the expense of their patients. My concern lies more with how the character of the physician is shaped within everyday clinical circumstances. For example, let us consider an on-call resident faced with the decision of whether to place a central line into her elderly patient. Some of the considerations may include the certain benefit to the patient from the immediacy of treatment delivery or waiting until the morning for a nurse practitioner to arrive and do a less invasive and less risky PICC line. However, the central line provides experience to the resident, boosting logged procedure numbers for the residency graduation requirements, and the patient can be nudged into consent either way. The ethical considerations are inseparable from the medical ones, and the physician's character plays an 
integral part in how she reasons. Here, it is not important what decision she arrives at (because both can be potentially medically beneficial), but rather how she arrives at the decision itself. In an environment that prizes competitive behavior and professionalism, the resident is less likely to have developed the capacity to reason in ways that are right, to weigh ethical considerations appropriately, not merely as a professional but also as a person of good character. A resident may, in such a situation, be more inclined to defer to protocol as a substitute for moral reasoning. Thus, while being a physician, theoretically, is ideal for one to live a meaningful life for the reasons mentioned prior, the focus on character reveals that the system is structured such that institutional concerns often override considerations of the moral sort. From the perspective of other ethical theories, it is perfectly fine for the physician to follow hospital protocol, which is in place not only to hold physicians' accountable but also to give them clear (deontological or utilitarian) guideline of how to behave when faced with certain moral considerations. A focus on character gives us the necessary insight about why sometimes crosschecking against rules and guidelines is not sufficient in and of itself, and possibly even detrimental for developing and sustaining moral dispositions.

In addition to medical standards that physicians follow, each hospital or practice center has its own set of regulations to ensure uniformity of procedures and quality patient care, which is one more avenue where a form of substitution of moral consideration takes place. For example, many hospitalists follow a 'ten systems checklist' while taking a patient's medical history. This ensures that doctors do not miss any crucial information about seemingly unrelated symptoms. Often though such checklists end up replacing a human connection with patients, and it becomes easy for a physician to dismiss the significance of such a connection because the protocols necessary to ensure quality patient care have been fulfilled. The doctor may rest easy in the fact that she has adhered to said standards of care for that situation and consequently, ethical considerations are gradually replaced by guidelines that appear to ensure uniformity of care and ethical behavior on the part of physicians. However, this is mere appearance of ethical behavior, for habitual and proper exercise of moral faculties is absent from consideration. Slowly, certain behaviors become scripted as normal as long as they are within the provided guidelines. I am not arguing here whether the patient benefits from guidelines and/or an empathic relationship (though they certainly do), rather that the ongoing process of character formation for the physician, which is crucial in of itself, has been limited and/or negatively affected. Professional ethical guidelines impede the formation of good character and the lack of habituating the right reasons affects our moral function when faced with moral consideration in our lives, both professional and personal.

One of my motivating concerns for pursuing this project has been the nature of the activity of being a physician, where healing patients has the potential and all the markers to be a labor of love. However, within the current environment, medical practice has now transformed into an activity that places a lot of emphasis on norms and standards of care. This is certainly so, for good reasons. Such standards were often a response to the early paternalistic attitudes in medicine by the state and by individual doctors. While the blowback to paternalism was intended to restore patient autonomy in medical decisions, it has also had unintended consequences of distancing the physician from the true human worth of their patients. Rules that are meant to ensure that patients are fully informed of their rights and allow the ability for patients to make decision for themselves may also often leave patients psychologically alone through that decision making process. More significantly for the purpose of this paper, it has discouraged many physicians from forming empathic bonds. In place of such bonds, physicians are trained to habituate 'appropriate' distance from the patient and embody professionalism. Often, 
in institutional settings, this translates to marking off checklists for efficiency and habituating a practice of discounting opportunities for responding empathically.

\section{"We can change" - malleability of character}

A lack of certain traits, which may not be fatally problematic to patient care per se, certainly affects the physician's character as a person. So far I have argued that physicians often fail to express appropriate moral affective response when it is appropriate to do so and may overlook the opportunity to form human connection with others. Importantly, these moral deficiencies are more clearly visible when we focus on character of the physician for the physician's sake.

An objection to this kind of project has been articulated in literature about situationism. This burgeoning field, in part, contends that ethical behavior is dependent more so on the situation than some notion of well-settled character. That is to say, different people react in similar ways in similar ethical situations (i.e. they have a trait local to the situation), and $a$ person reacts differently (i.e. with inconsistency of an overarching global trait within that person) in different moral situations (Doris 2002; Harman 1999 \& 2000). The central concern is that there is no such thing as a stable entrenched character. It is a matter of how a physician responds to triggered affects set in a particular situation - affects such as feeling empathic, guilty, being in a fairly good or bad mood. That is to say, the behavior is situation dependent rather than character dependent. While this debate is not the focus of this paper, it is pertinent to the thesis in a certain way and here, I merely bring out the ways that this debate bears on character (or lack thereof) within everyday clinical norms.

Christian Miller who has written about a 'compromise' between the two frameworks of virtue ethics and situationism points out that with the absence of longitudinal data, one can only claim that the current (controversial) data is compatible with the notion that there are no global character traits and not a conclusive proof of it. To make any claims about the absence or presence of global traits, “...we would need to perform longitudinal experiments which track subjects over time as they find themselves in both similar and different help-eliciting circumstances.” Furthermore, “... social psychologists seem justified in predicting that (other things being equal) the majority of subjects would help in certain situations which are different from those that have already been tested, provided the right psychological triggers for helping are also in place" $(2009,255)$. That is to say, we may not have disparate local traits, giving us a highly fragmented self; rather there are "structures at work" (263) such that if certain psychological triggers (such as empathy, good mood, etc.) are set, the person in question would respond in the same fashion across a variety of circumstances.

Miller's point is precisely in line with how I view the current everyday conditions in the medical field. When one works in an environment that constantly elicits certain affects and inhibits others, we can expect consistency of behavior. As Miller points out, the studies cited by moral psychologists such as John Doris (2002) do not measure $a$ person over a series of similar sorts of experiences. In the case of a physician, how empathically or compassionately a physician responds to different patients is dependent on how one's character is molded to and within certain social structures. For example, a doctor may harbor racist or homophobic tendencies and treat minorities with merely adequate medical care to avoid a lawsuit. We would definitely say that her character is lacking in certain ways. Furthermore, let us assume that she does not respond with the same racist or homophobic tendencies if her coffee server was a minority; in fact she may even tip generously in that scenario. Does she cease to have a 
deficiency in her character because of such a case of 'inconsistency'? We would think not. ${ }^{13}$ Her racist tendencies are situation-dependent in the sense that they manifest themselves in certain social context but nonetheless form an essential constituent of her identity, of who she is. I would argue that certain power structures do come into play when an individual occupies the role of a physician that are absent for that individual when they are merely a customer at a cash register. They would still be considered to be prejudiced, if the color of the patient's skin elicits certain negative affect or behavior from one as a physician. Furthermore, in any other situation, even outside of the clinical settings, if similar power structures come into play, it is reasonable (and compatible with existing psychological studies that Doris cites) that the physician will respond with similar racist tendencies. When similar affects are elicited or similar power structures come into play, the physician will behave in ways similar to how they behave in clinical settings.

Another objection to this project may take the form that a focus on the character of the physician is decentered from the telos of the profession does not serve much purpose because one cannot change a person's fundamental character; one cannot make a cruel person be compassionate. Therefore, it makes sense to keep our focus solely on patient care to ensure the least amount of harm to others. This certainly may be true in the short term. Some doctors will be unsympathetic or completely detached from their patients regardless, and such traits may also be bleeding into their professional and/or personal lives when they fail to recognize opportunities to respond with the appropriate moral dispositions.

However, I agree with Rosalind Hursthouse (1999, 113-119) in her assessment that characters can be changed, can be molded if one attempts (hard enough) to habituate certain virtues. Hursthouse emphasizes the moral education of emotions and of being trained to respond appropriately for the right reasons in any given situation. This emotional response is not completely restrained to one's upbringing or innate personality; it can be gradually transformed through effort and education. She states:

It certainly does not follow that anyone subject to such reactions can shrug them off and say, 'Oh well; they are beyond my control; I just can't help reacting that way.' For since we know that some re-training is possible, and do not know when, if ever, it ceases to be effective, anyone decent must be anxiously seeking ways to control them, refusing to give up hope. $(1999,116)$

That is to say, an argument that some residents / physicians have had deficient characters prior to, or independent of, medical training and are unlikely to change, does not give due credit to the idea that as humans, we can always strive to change even deeply embedded traits. And perhaps, we should always aim for environments that would be conducive to better character formation. Furthermore, just as good training is likely to inculcate the right attitudes in physicians, bad training can also gradually affect physicians of good character. There are many physicians who do care, who do desire to do good, and who do good everyday. However, the current infrastructure is set up in a way that even the best intentioned amongst us can persevere only so much before regulatory resistance drags on the fluidity of the performance of that good. And there are a number of factors that habituate a particular way of reasoning which is not conducive to inculcating good character, such as being unable to relate to patients' narratives specific to their socio-economic status, stress of time constraints, competitive nature of medical training, expectation of substituting professionalism for humanly bonds, referring to regulations instead of exercise of moral faculty, and continual crosschecking with external monitors and incentives instead training to align the right motives with 
good character. Thus, moral damage to good people becomes inevitable with time, as their deliberations are dislocated by privilege, incentives, and through often well-intentioned regulations and standards of care.

A focus on the character of the physician for the physician's own sake allows us to see more clearly the moral harm done within everyday clinical norms, and perhaps we can alter some of those norms to preserve the exercise of our moral faculties - not merely for the patients' sake but for the physicians' - such that they can respond in more adequately responsive ways. Furthermore, I acknowledge that an examination of the character of the physician as a human being cannot be unlinked from the examination of the good physician, but the former concentrates on the character for the sake of the person and such an examination has value in of itself. In this respect, this project is less concerned with (patient) outcomes and more with the processes of life that physicians occupy. I have argued that it is necessary to examine the physician's character, occasionally decentering patient concerns as our sole ethical guide, and that doing so allows us to see the ways that the clinical norms, often geared toward providing quality patient care, adversely impact the character of physicians. Ultimately, I claim that we ought to see our physicians as more than their medical contributions. We ought to see them perhaps as (fallible) humans.

Acknowledgments I would like to thank Alison Reiheld, PhD. and Erik Krag, PhD. for their constructive feedback on earlier drafts and the invaluable anonymous reviewers for their feedback on the latter versions. This paper also would not have been possible without the indispensable input from Huzaifa Quaizar, MD.

\section{Endnotes}

\footnotetext{
${ }^{1}$ For detailed discussion on the teleological goals of medicine, see Edmund D. Pellegrino's The Philosophy of Medicine Reborn (2008) that extensively explores the idea of 'good of the patient.' He argues this 'good' falls into four categories: "the patient's concept of the ultimate good," "biomedical and techno-medical good," "the patient's concept of his own good," and "the good of patient as a person" (163-186). He further writes about the doctor-patient relationship that is geared towards ends and purposes of the relationship, where the ends of medicine "are ultimately the restoration or improvement of health, and more proximately, to heal, i.e., to cure illness and disease or, when this is not possible, to care and help the patient to live with residual pain, discomfort, or disability" (200). ${ }^{2}$ I do not see this distinction of examining virtue without an emphasis on the telos of the profession necessarily in opposition to Alasdair Macintyre (2007) explication of virtue in his book, After Virtue. He states: "A virtue is an acquired human quality the possession and exercise of which tends to enable us to achieve those goods which are internal to practices and the lack of which effectively prevents us from achieving any such goods" (191). For MacIntyre, there are universal virtues to all practices (justice, courage, honesty, and history) but that each practice (such as that of being a physician) will have its own set of unique virtues as well that can be generated from the telos of the profession. However, for MacIntyre, there is no inconsistency in appealing to the requirements of a virtue (such as competitiveness nurtured amongst residents) to criticize the practice as it is done today. More importantly, there has to be "a telos which transcends the limited good of practices by constituting the good of a whole human life" (203). That is to say, while examining virtues generated through the framework of medicine is important, there still needs to be an examination of a whole human life.

${ }^{3}$ For an account of eudaimonia in line with the intent of this paper, see Hursthouse (1999) where she writes that eudaimonia is the "notion of 'true (or real) happiness', or 'the sort of happiness worth having'. We tend to say that someone may be happy, though not truly happy, if they are living in a fool's paradise, or engaged in what we know is a pointless activity, or brain-damaged and leading a life of a happy child"(10).

${ }^{4}$ I use the term script as Alison Bailey's describes it as the idea of performative scripts as "a person's gestures, language, attitudes, concept of personal space, gut reactions to certain phenomena, and body awareness" (2000, 289).
} 
${ }^{5}$ American Academy of Family Physicians (2013) cites that 'the average net income of family physicians $(\$ 190,000)$ allows them to effectively pay off student loans in a reasonable amount of time and comfortably support their families.' Family physicians are generally near the bottom of the pay scale for physician compensation, with specialist earning on average twice as much (Vaugh et al. 2010).

${ }^{6}$ The U.S. Census Bureau $(2014,5)$ cites U.S. median household income was $\$ 53,657$ in 2014. More than $90 \%$ of the U.S. population in 2014 was below the $\$ 150,000$ mark (23).

${ }^{7}$ Kraus \& Keltner (2013) study showed that "social class shapes essentialist conceptions of social class hierarchy that, in turn, impact endorsement of punitive judgments. In this way, social class leads to differences in the way individuals explain their rank in society and the forms of punishment they support in their everyday lives" (259). That is to say, relative to lower class, upper class individuals were more likely to believe in essentialist explanations of distribution of wealth, which in turn affected their perception of retributive justice.

Overall, studies have also shown that people tend to discount the role of the unearned privilege they possess, in how much success they achieve. For example, in a focus group study (Gallagher 2003), it showed that people having white privilege did not think that race played a part in people's access to opportunities. The author argued that maintaining belief that we live in a color blind society helps Whites process their own success and the failure of others.

Another study (Castilla 2010) showed that "bias can be triggered by attempts to reduce it, particularly in organizational contexts that emphasize meritocratic values." This is to say, that organizations that explicitly tout meritocratic values, may end up committing more harm against the already disadvantaged, all the while, maintaining their belief that bonuses and raises are awarded on basis of hard work.

${ }^{8}$ Here is a sample of one such encounter of a physician with a cancer-patient faced with their impending mortality: Patient: "I don't know what the average person does in 2 years, 3 years, a year?" Physician: "I think that ... you certainly could live 2 or 3 years. I think it would be very unlikely ... But I would say that an average figure would be several months to a year to a little bit more" [Encounter 2] (Morse et al. 2008).

${ }^{9}$ An exception maybe when there is a medical emergency within one's immediate family. Such a case further supports my position against compartmentalization of role-related obligations.

${ }^{10}$ In an extreme display of cruelty, in South Gloucestershire, England, patients with learning disabilities were physically and psychologically abused and tortured by nurses and other staff members. In response, the Department of Health in the United Kingdom released a report that made a massive number of recommendations to avoid any future breakdown of standards (DHS 2012). The instances of abuse were egregious and a micro-level review was appropriate.

11 "Quality measures appear to be a small yet emerging component of total compensation for physicians....primary care physicians reported that $3 \%$ of their total compensation was based upon measures of quality" (Medical Group Management Association Survey 2013).

12 "For example, in a study (Saitta \& Hodge 2012) about apology by doctors for unexpected medical outcomes, authors noted that "simple apology allows physicians to remain true to their honesty and integrity while exhibiting their humanity and providing some much-needed closure to their patients and their patients' families. It is the amelioration of this anger that leads to less costly litigation. Therefore, we believe that if a physician's jurisdiction has the appropriate legislation, he or she should consider apologizing for an unexpected medical outcome. It may be the best medicine available to soothe the feelings of a patient or family and to avoid a malpractice lawsuit." (emphasis mine) The integrity of the physician would then eventually take a back seat to considerations of litigation.

${ }^{13}$ This is reminiscent of views on expressed in Jean Paul Sartre's The Anti-Semite and the Jew (1995, 8). Sartre reminds us that we cannot view anti-Semitic tendencies as mere opinions or "localized" behaviors elicited by certain people. It is problematic if we view an anti-Semitic person ... "as a composite whose elements can be separated, we look upon persons and characters as mosaics in which each stone coexists with the others without that coexistence affecting the nature of the whole. Thus anti-Semitic opinion appears to us to be a molecule that can enter into combination with other molecules of any origin whatsoever without undergoing any alteration. A man may be a good father and a good husband, a conscientious citizen, highly cultivated, philanthropic, and in addition an anti-Semite. ...If he does not like them [Jews], we say, it is because his experience has shown him that they are bad, because statistics have taught him that they are dangerous, because certain historical factors have influenced his judgment. Thus this opinion seems to be the result of external causes, and those who wish to study it are prone to neglect the personality of the anti-Semite..." (emphasis mine). 


\section{References}

American Academy of Family Physicians. 2013. "Lifestyle \& Income for Family Physicians." Accessed February 15, 2016. http://www.aafp.org/medical-school-residency/choosing-fm/lifestyle.html.

Aristotle. 1989. Nicomachean Ethics. Translated by D. Ross, Rev. J. L. Ackrill \& J. O. Urmson. Oxford, UK: Oxford University Press.

Bailey, Alison. 2000. "Locating Traitorous Identities." In Decentering the Center: Philosophy for a Multicultural, Postcolonial, and Feminist World, edited by Uma Narayan and Sandra Harding, 283-298. Indianapolis, Ind.: University of Indiana Press.

Braddock, C.H., III and L. Snyder. 2005. "The Doctor will see you shortly. The Ethical Significance of Time for the Patient-physician Relationship." Journal of General Internal Medicine 20:1057-62.

Carse, Alisa L. 2005. "The Moral Contours of Empathy." Ethical Theory and Moral Practice 8 (1/2): 169-95.

Castilla, Emilio J., and Stephen Benard. 2010. "The Paradox of Meritocracy in Organizations." Administrative Science Quarterly 55: 543-576.

Canale, Del S., D.Z. Louis, V. Maio, X. Wang, G. Rossi, M. Hojat, J.S. Gonnella. 2012. “The Relationship between Physician Empathy and Disease Complications: An Empirical Study of Primary Care Physicians and their Diabetic Patients in Parma, Italy." Academic Medicine 87 (9):1243-9.

DeNavas-Walt, Carmen and Bernadette D. Proctor. 2015. Income and Poverty in the United States: 2014. U.S. Census Bureau. Washington, DC.: U.S. Government Printing Office. Accessed February 15, 2016. https:// www.census.gov/content/dam/Census/library/publications/2015/demo/p60-252.pdf

DHS: Department of Health. 2012. "Transforming Care: A National Response to Winterbourne View Hospital, Department of Health Review: Final Report.” Accessed November 1, 2013. https://www.gov.uk/ government/uploads/system/uploads/attachment_data/file/213215/final-report.pdf.

Doris, John. 2002. Lack of character: Personality and moral behavior. Cambridge: Cambridge University Press.

Gallagher, Charles A. 2003. "Color-Blind Privilege: The Social and Political Functions of Erasing the Color Line in Post Race America, Race, Gender \& Class." Privilege and Race, Gender, and Class 10 (4): 22-37.

Gardiner, P. 2003. “A Virtue Ethics Approach to Moral Dilemmas in Medicine.” Journal of Medical Ethics 29: 297-302.

Harman, Gilbert. 1999. "Moral Philosophy meets Social Psychology: Virtue Ethics and the Fundamental Attribution Error." Proceedings of the Aristotelian Society 99:315-332.

- 2000. "The Nonexistence of Character Traits." Proceedings of the Aristotelian Society 100: 223-226.

Hojat, Mohammadreza, Michael J. Vergare, Kaye Maxwell, George Brainard, Steven K. Herrine, Gerald A. Isenberg, Jon Veloski, and Joseph S. Gonnella, 2009. "The Devil is in the Third Year: A Longitudinal Study of Erosion of Empathy in Medical School.” Academic Medicine 84 (9): 1182-1191.

Hursthouse, Rosalind. 1999. On Virtue Ethics. Oxford, UK: Oxford University Press.

Jansen, Lynn A. 2000. "The Virtues in their Place: Virtue Ethics in Medicine." Theoretical Medicine and Bioethics 21 (3): 261-275.

Katz, D.A., G.C. Williams, R.L. Brown, T.P. Aufderheide, M. Bogner, P.S. Rahko, and H.P. Selker. 2005. "Emergency Physicians' Fear of Malpractice in Evaluating Patients with Possible Acute Cardiac Ischemia." Annals of Emergency Medicine 46 (6): 525-33.

Kessler, Daniel and Mark McClellan. 1996. “Do Doctors Practice Defensive Medicine?” The Quarterly Journal of Economics 111 (2): 353-390.

Kraus M.W. and D. Keltner. 2013. "Social Class Rank, Essentialism, and Punitive Judgment." Journal of Personality and Social Psychology 105 (2): 247-61.

Lelorain, S., A. Dolbeault Brédart, and S. Sultan. 2012. "A Systematic Review of the Associations between Empathy Measures and Patient Outcomes in Cancer Care.” Psycho-Oncology 21:1255-1264.

Linzer M., T.R. Konrad, J. Douglas, et al. 2000. "Managed Care, Time Pressure, and Physician Job Satisfaction: Results from the Physician Worklife Study." Journal of General Internal Medicine 15:441-50.

MacIntyre, Alasdair. 2007. After Virtue. Notre Dame, IN: University of Notre Dame, 3rd Edition.

Maslach, C., and M.P. Leiter. 1997. The Truth about Burnout. San Francisco: Jossey Bass.

Maslach, C., S.E.Jackson, and M.P. Leiter. 1996. MBI: The Maslach Burnout Inventory Manual. Palo Alto, CA: Consulting Psychologists Press.

Medical Group Management Association Survey. 2013. "Physician Compensation includes Quality and Patient Satisfaction Components." Accessed February 15, 2016. http://www.mgma.com/about/mgma-press-room/ press-releases/physician-compensation-includes-quality-and-patient-satisfaction-component.

Mello, Michelle M., Emily R. Carrier, James D. Reschovsky, David A. Katz. 2013. "High Physician concern about Malpractice Risk predicts more Aggressive Diagnostic Testing In Office-Based Practice." Health Affairs 32:1383-1391.

Miller, Christian. 2009. "Empathy, Social Psychology, and Global Helping Traits." Philosophical Studies: An International Journal for Philosophy in the Analytic Tradition 142 (2): 247-275. 
Montgomery, Kathryn. 2005. How Doctors Think: Clinical Judgment and the Practice of Medicine. New York, NY: Oxford University Press.

Morse, Diane, Elizabeth Edwardsen, and Howard Gordon. 2008. "Missed Opportunities for Interval Empathy in Lung Cancer Communication." Archives of Internal Medicine 168 (17): 1853-1858.

Neumann, Melanie. Friedrich Edelhäuser, et.al. 2011. "With Medical Students and Residents." Academic Medicine 86 (8): 996-1009.

Pellegrino, Edmund D. 2008 (1995). The Philosophy of Medicine Reborn: A Pellegrino Reader. Notre Dame, IN: University of Notre Dame.

Pellegrino, Edmund D., and David C. Thomasma. 1993. The Virtues in Medical Practice. New York City, NY: Oxford University Press.

Piper, Adrian. 1991. "Impartiality, Compassion, and Modal Imagination." Ethics 101 (4): 726-57.

Putman, D.A. 1988. "Virtue and the Practice of Modern Medicine." The Journal of Medicine and Philosophy 13 (4):433-43.

Reverby. Susan M. 2012. "Ethical Failures and History Lessons: The U.S. Public Health Service Research Studies in Tuskegee and Guatemala." Public Health Reviews 34 (1): 1-18.

Rosen, Ilene M., Phyllis A. Gimotty, Judy A. Shea, and Lisa Bellini. 2006. "Duty Hours: Evolution of Sleep Quantity, Sleep Deprivation, Mood Disturbances, Empathy, and Burnout among Interns." Academic Medicine 81 (1): 82-85.

Saitta, Nicole and Samuel D. Hodge. 2012. "Efficacy of a Physician's Words of Empathy: An Overview of State Apology Laws.” Journal of the American Osteopathic Association 112 (5): 302-306.

Sartre, Jean-Paul. 1995 (1948). Anti-Semite and Jew: An Exploration of the Etiology of Hate. New York City, NY: Schocken.

Schaufeli, W. B., and E. R.Greenglass, 2001. "Introduction on a Special Issue on Burnout and Health." Psychology \& Health 16: 501-510.

Shanafelt T, J. Sloan, and T. Habermann. 2003. "The Well-being of Physicians.” American Journal of Medicine 114 (6): 513-519.

Shanafelt T.D., S. Boone, L. Tan, et al. 2012. "Burnout and Satisfaction with Work-Life Balance among U.S. Physicians relative to the general U.S. Population. Archives of Internal Medicine 172 (18): 1377-1385.

Snow, Nancy. 2000. "Empathy.” American Philosophical Quarterly 37 (1): 65-78.

Stepien, K.A., and A. Baernstein. 2006. "Educating for Empathy. A Review." Journal of General Internal Medicine 21 (5): 524-530.

Studdert, David M., Michelle M. Mello, William M. Sage, Catherine M. DesRoches, Jordon Peugh, Kinga Zapert, and Troyen A. Brennan. 2005. "Defensive Medicine among High-risk Specialist Physicians in a Volatile Malpractice Environment." Journal of the American Medical Association, 293 (21): 2609-2617.

Thomas, Matthew R., Liselotte N. Dyrbye, Jefrey L. Huntington, Karen L. Lawson, Paul J. Novotny, Jeff A. Sloan, and Tait D. Shanafelt. 2007. "How Do Distress and Well-being Relate to Medical Student Empathy? A Multicenter Study." Journal of General Internal Medicine 22 (2): 177-183.

Vaughn, Bryan T., Steven R. DeVrieze, Shelby D. Reed, and Kevan A. Schulman. 2010. "Can we close the Income and Wealth Gap between Specialists and Primary Care Physicians?" Health Affairs 29 (5): 933-940.

West, Colin P. Angelina D. Tan, Thomas M. Habermann, Jeff A. Sloan, and Tait D. Shanafelt. 2009. "Resident Fatigue and Distress with perceived Medical Errors." Journal of the American Medical Association 302 (12): 1294-1300. 